\title{
Mechanical Properties of Optical Dielectric Thin Films Deposited by the Ion Plating Technique
}

\author{
Christine Mahodaux $\left({ }^{1}\right)$, Hervé Rigneault $\left({ }^{1}\right)$, Hugues Giovannini $\left({ }^{1}\right)$, \\ Ludovic Escoubas $\left({ }^{1}\right)$ and Paul Morreti $\left({ }^{2}\right)$ \\ $\left({ }^{1}\right)$ Laboratoire d'Optique des Surfaces et des Couches Minces, UPRES A CNRS 6080, ENSPM, \\ Domaine Universitaire de Saint-Jérôme, 13397 Marseille Cedex 20, France \\ $\left({ }^{2}\right)$ Laboratoire de Physico-Chimie des Matériaux Luminescents, UMR CNRS 5620, Université \\ Claude Bernard Lyon I, 43 boulevard du 11 Novembre 1918, 69622 Villeurbanne, France
}

(Received: July 7; accepted: October 20, 1997)

PACS.68.60.Bs - Mechanical and acoustical properties
PACS.68.60.Dv - Thermal stability; thermal effects
PACS.68.55.Ln - Defects and impurities: doping, implantation, distribution, concentration, etc.

\begin{abstract}
Stress in thin films deposited by Reactive Low-Voltage Ion Plating (RLVIP) is studied in air and at room temperature. A multilayer stack, composed of tantalum pentoxide and silicon dioxide layers, is considered and the interactions layer to layer turn out to have no effect as regards to the final bending. The evolutions of plate bending after annealing show the possibility to reduce the stress as well as the absorption for tantalum pentoxide thin films. Finally, ion implantation, with ions such $\mathrm{He}^{+}$or $\mathrm{Xe}^{+}$accelerated at energy in the $\mathrm{MeV}$ range, proves to be also a way to vary and reduce the stress in thin films.
\end{abstract}

\section{Introduction}

Modern optics requires components, such as mirrors, antireflection coatings, filters ..., as highly efficient as possible. Consequently, understanding and controlling the stress effects in thin films turns out to be crucial in order to reduce the substrate bending as well as to avoid defects such as cracks and bulges.

Broadly speaking, residual stress, in air and at room temperature, can be divided into three parts [1-3]: a thermal stress, due to different thermal-expansion coefficients; an extrinsic stress, due to impurities in the film connected with the interactions between the film and the environment; and finally, an intrinsic stress, due to the deposition process. In a word, the residual stress depends on various parameters linked with the materials, the deposition process and the environment. Generally, thin films made by modern techniques, such as Ion Beam Sputtering, Ion Beam Assisted Deposition or Ion Plating, are dense and show a compressive intrinsic stress, whereas thin films made by classical evaporation or sputtering are porous and show a tensile intrinsic stress.

Our study deals with tantalum pentoxide films, $\mathrm{Ta}_{2} \mathrm{O}_{5}$, and silicon dioxide, $\mathrm{SiO}_{2}$, deposited by Reactive Low-Voltage Ion Plating (RLVIP) [4], on silica substrate. The RLVIP is a highenergy process and the evaporation is performed in the presence of a mixture of argon and 
oxygen gas $\left(10^{-4}\right.$ torr). The RLVIP thin films are amorphous, homogeneous and dense, and are free from water sorption and desorption. Furthermore, they have all been deposited onto unheated substrates. Thus, it can be considered that the films, when used in air and at room temperature, show only an intrinsic stress.

This paper, devoted to study the stress in RLVIP optical thin films, such as $\mathrm{Ta}_{2} \mathrm{O}_{5}$ and $\mathrm{SiO}_{2}$, briefly presents, in Section 2, the elastic model used to connect the stress and the deflection together with the experimental set-up, which is implemented to measure the bending of the plates. Then, in Section 3, the results of typical stress measurements are presented for single layers and multilayer stacks deposited with RLVIP. In particular, we show that the deflection of a multilayer stack can be predicted, knowing the stress in the various constituent materials of the multilayer.

Since optical absorption is a key parameter in thin film manufacture, Section 4 discusses the correlation between stress, absorption and thermal annealing.

Finally, Section 5 presents, for the first time of our knowledge, results obtained when thin films are implanted with high-energy ions such as helium and xenon. We show that in any case the stress can be strongly affected depending on the species doses.

\section{Experiment}

In order to measure the residual stress, we use the macroscopic elastic model reported by Stoney [5], which links the variation of the deflection at the film center $\Delta h$ with the residual film stress and gives the following formula:

$$
\sigma_{\mathrm{f}}=\frac{4}{3} \frac{E_{\mathrm{s}}}{\left(1-\nu_{\mathrm{s}}\right)} \frac{t_{\mathrm{s}}^{2}}{t_{\mathrm{f}}} \frac{\Delta h}{d_{\mathrm{s}}^{2}},
$$

where: $\sigma_{\mathrm{f}}$ is the residual stress in the film; $E_{\mathrm{s}}$ and $\nu_{\mathrm{s}}$ are the substrate Young's modulus and Poisson ratio; $t_{\mathrm{s}}$ and $d_{\mathrm{s}}$ are the substrate thickness and diameter; $t_{\mathrm{f}}$ is the film thickness; $\Delta h=h_{2}-h_{1}$, where $h_{2}$ is the deflection of the substrate when the film has been deposited and $h_{1}$ the deflection of the substrate alone before deposition.

This rather simple formula is based on the following hypotheses: the stress is assumed to be planar and biaxial and the strain isotropic, the materials have equivalent elastic properties, and finally the thin film must be in an elastic state, with perfect adhesion.

Consequently, in order to measure the deflection $\Delta h$, and therefore the residual stress, we have implemented an interferometric method which has the advantage of being suitable to any kind of samples. More precisely, a Fizeau interferometer, see Figure 1, enables, thanks to image processings, to achieve a $3 \mathrm{D}$ outline of the film and thus to measure the deflection $\Delta h$ at the film center. It should be noted that the calibrated optical flat used is polished to better than $\lambda / 20$ at $\lambda=632.8 \mathrm{~nm}$, which leads to an overall $\lambda / 10$ precision on the $\Delta h$ values.

\section{Multilayer Stack}

The main task in optical thin films design is to find the multilayer that would realize the desired optical function together with being workable in the coating plant. This last point requires to take into account the stress as a key parameter in order to avoid cracks or bulges in the films. It is therefore important to be able to predict the stress in multilayer stacks. This can be done by extending the Stoney formula $[5,6]$. The elastic model gives, for a multilayer stack, 

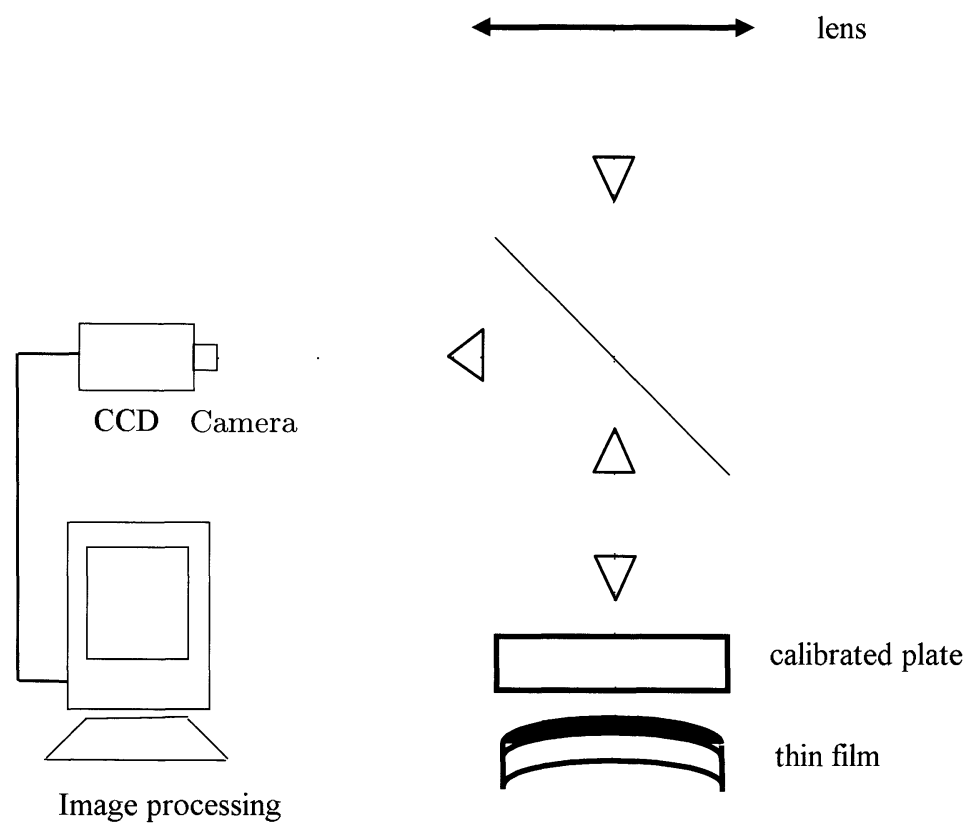

Fig. 1. - Set-up - Fizeau interferometer.

a relation between the stress in every layer and the whole deflection, $\Delta H$, of the stack:

$$
\Delta H=\sum_{i} \Delta h_{i}=\sum_{i} \frac{3}{4} \frac{\left(1-\nu_{\mathrm{s}}\right)}{E_{\mathrm{s}}} \frac{t_{i}}{t_{\mathrm{s}}^{2}} \sigma_{i} d_{\mathrm{s}}^{2},
$$

where $\sigma_{i}$ is the stress in the $i$ th layer, $t_{\imath}$ the thickness of the $i$ th layer, $\Delta h_{i}$ the variation of the deflection due to the $i$ th layer when deposited on the substrate, $\Delta H$ the variation of the deflection due to the deposition of the whole stack on the substrate.

In equation (2), the layer to layer interaction terms have been neglected since they show a dependency in $t_{i} / t_{\mathrm{s}}$, with $t_{\mathrm{s}} \gg t_{i}$. This leads to consider only the interaction of each layer with the substrate for the prediction of the final deflection $\Delta H$.

In order to control the validity of this hypothesis, we consider a multilayer stack: substrate/BHBHBH/air, where $\mathrm{H}$ and $\mathrm{B}$ are high and low index layers of $\mathrm{Ta}_{2} \mathrm{O}_{5}$ and $\mathrm{SiO}_{2}$ $\left(n_{\mathrm{H}}=2.22 ; n_{\mathrm{B}}=1.48\right)$ whose optical thickness is $\lambda / 4(\lambda=548 \mathrm{~nm})$. This stack is a mirror which exhibits a reflectivity of $R=70 \%$. The deflection value measured for this structure is $\Delta H=951 \mathrm{~nm}$ to within $3 \%$, and is found to be due to a compressive stress. We also perform measurements on single layers of $\mathrm{SiO}_{2}$ and $\mathrm{Ta}_{2} \mathrm{O}_{5}$, deposited in similar conditions. They both show a compressive stress. From the values given in Table I, we can then calculate the deflection that the mirror ought to show by assuming, according to equation (2), that only the interaction of each layer with the substrate is significant. The calculation gives $\Delta H=925 \mathrm{~nm}$, related to a compressive stress. This calculated value for $\Delta H$ is obviously not exactly the experimental one, but only - and undoubtedly — in very good agreement with it within the experimental uncertainty. 
Table I. - Stresses for single layers.

\begin{tabular}{|c|c|c|c|}
\hline & Thickness & Deflection & Stress \\
\hline $\mathrm{Ta}_{2} \mathrm{O}_{5}$ layer & $854 \mathrm{~nm}$ & $1.2 \mu \mathrm{m}$ & $-24 \mathrm{GPa}$ \\
\hline $\mathrm{SiO}_{2}$ layer & $646 \mathrm{~nm}$ & $1.8 \mu \mathrm{m}$ & $-44 \mathrm{GPa}$ \\
\hline
\end{tabular}

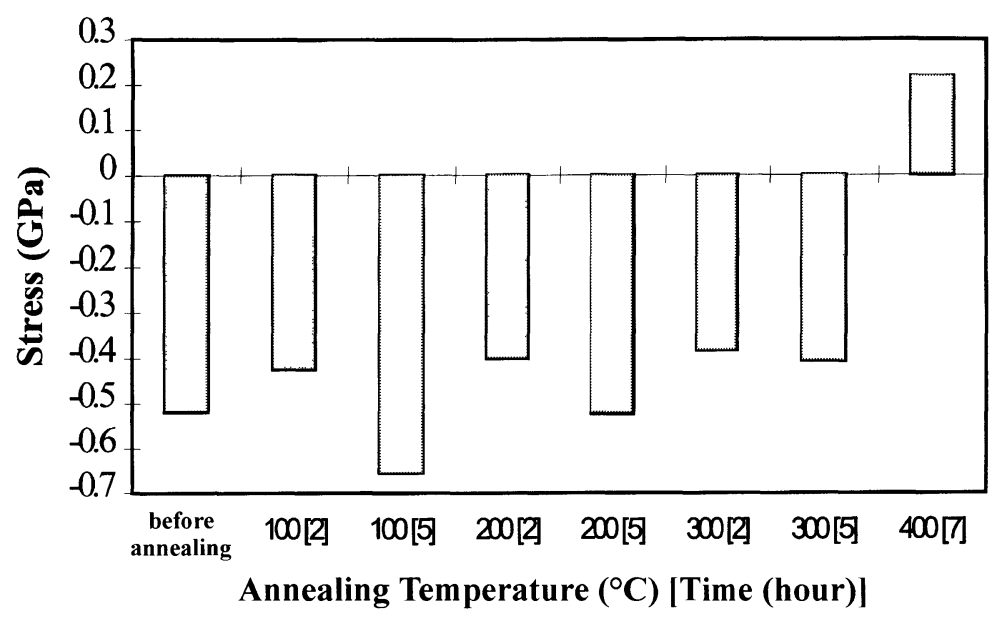

Fig. 2. - Stresses for a $\mathrm{Ta}_{2} \mathrm{O}_{5}$ thin film on silica substrate after several annealings.

Therefore, it seems possible to predict the deformation showed by any multilayer $\left(\mathrm{Ta}_{2} \mathrm{O}_{5}\right.$, $\mathrm{SiO}_{2}$ ) stack and to use this prediction as an additional mechanical criterion for the synthesis of multilayer stack.

\section{Thermal Annealing}

Thermal annealing is commonly used in thin films technology, especially to attempt to reduce the optical absorption and the scattering level in thin films. Since RLVIP deposited films are known to be able to sustain annealing at relatively high temperature, we decide to study annealing effects on the stress of $\mathrm{Ta}_{2} \mathrm{O}_{5}$ layers.

Therefore, thermal annealings are successively applied to the layer at various temperatures and durations as follows: $2 \mathrm{~h}$ at $100{ }^{\circ} \mathrm{C}, 5 \mathrm{~h}$ at $100{ }^{\circ} \mathrm{C}, 2 \mathrm{~h}$ at $200{ }^{\circ} \mathrm{C}$ and finally $7 \mathrm{~h}$ at $400{ }^{\circ} \mathrm{C}$. Figure 2 shows the values of the stress measured after each annealing; tensile stress is considered to be positive while compressive stress is negative. As it can be seen from Figure 2, the film before annealing shows a strong compressive intrinsic stress which value $(-0.5 \mathrm{GPa})$ actually remains nearly constant until the last annealing performed at $400{ }^{\circ} \mathrm{C}$. The latter results in a relaxation of the compressive stress as well as a generation of a weak tensile stress. It should be noticed that this transition from compressive to tensile stress around $400{ }^{\circ} \mathrm{C}$ is also observed on samples directly annealed at this temperature, as reported in Table II, even for annealing times as short as one hour.

In order to check the optical properties of thin films, we have measured, see Tables III and IV, the refractive indices and the thicknesses of the films before and after annealings. For this, we have used the $m$-lines technique [7], based on the optical excitation of electromagnetic 
Table II. - Stresses for two $\mathrm{Ta}_{2} \mathrm{O}_{5}$ thin films before and after annealing at $400{ }^{\circ} \mathrm{C}$.

\begin{tabular}{|c|c|c|c|}
\hline & $\begin{array}{c}\text { Stress before annealing } \\
(\mathrm{GPa})\end{array}$ & $\begin{array}{c}\text { Duration of annealing } \\
\text { (hour) }\end{array}$ & $\begin{array}{c}\text { Stress after annealing } \\
(\mathrm{GPa})\end{array}$ \\
\hline Layer 2 & -0.59 & 10 & +0.28 \\
\hline Layer 3 & -0.46 & 1 & +0.25 \\
\hline
\end{tabular}

Table III. - m-lines measurements, refractive indices before and after annealing (the refractive indices of $\mathrm{Ta}_{2} \mathrm{O}_{5}$ thin films are measured before and after annealing by Transverse Electric-TEand Transverse Magnetic - TM- modes excitation).

\begin{tabular}{|c|c|c|c|c|c|c|}
\hline $\begin{array}{c}\text { Refractive } \\
\text { index }\end{array}$ & \multicolumn{2}{|c|}{$\begin{array}{c}\text { Layer 1 } \\
\text { successive } \\
\text { annealing }\end{array}$} & \multicolumn{2}{|c|}{$\begin{array}{c}\text { Layer } 2 \\
400^{\circ} \mathrm{C} \\
(10 \text { hours })\end{array}$} & \multicolumn{2}{|c|}{$\begin{array}{c}\text { Layer } 3 \\
400^{\circ} \mathrm{C} \\
(1 \text { hour })\end{array}$} \\
\hline & $\mathrm{TE}$ & $\mathrm{TM}$ & $\mathrm{TE}$ & $\mathrm{TM}$ & $\mathrm{TE}$ & $\mathrm{TM}$ \\
\hline $\begin{array}{c}\text { before } \\
\text { annealing }\end{array}$ & 2.269 & 2.272 & 2.269 & 2.273 & 2.273 & 2.275 \\
\hline $\begin{array}{c}\text { after } \\
\text { annealing }\end{array}$ & \multicolumn{2}{|c|}{2.246} & \multicolumn{2}{|c|}{2.245} & \multicolumn{2}{|c|}{2.250} \\
\hline
\end{tabular}

resonances in the layers by using a prism coupling method. This technique enables to achieve a precision of $10^{-3}$ for the refractive index and of $1 \mathrm{~nm}$ for the thickness.

Before annealing, as reported in Table III, all the three films show a weak optical anisotropy of about $3 \times 10^{-3}$. This anisotropy disappears after an annealing at $400^{\circ} \mathrm{C}$ while the refractive indices decrease of about $2 \times 10^{-2}$ and the thicknesses increase of about $10 \mathrm{~nm}$, as seen in Table IV. This behavior could be related to a decrease of the film density. This last point must be confirmed, for instance by performing Rutherford Back Scattering (RBS) spectroscopy.

In order to complete our annealing investigations, we present now some results concerning the optical absorption in RLVIP $\mathrm{Ta}_{2} \mathrm{O}_{5}$ films. Figure 3 gives the absorption measured by the photothermal deflection technique [8] in the film which has undergone successive annealings presented in Figure 2. This technique enables a $500 \mu \mathrm{m} \times 500 \mu \mathrm{m}$ absorption mapping. It is therefore possible to follow the evolution of the absorption related to localized defects into the film after successive thermal annealings as well as the mean absorption. It can be seen, from Figure 3, that the mean absorption values decrease after each annealing, to finally reach 20 $\operatorname{ppm}\left(1 \mathrm{ppm}=10^{-6}\right)$. With regards to the absorption measured on localized defects, they vary randomly, nevertheless, after the last annealing, all the absorptions have decreased consistently.

Table IV. - m-lines measurements, thicknesses before and after annealings.

\begin{tabular}{|c|c|c|c|}
\hline Thickness & Layer 1 & Layer 2 & Layer 3 \\
\hline before annealing & $425 \mathrm{~nm}$ & $427 \mathrm{~nm}$ & $427 \mathrm{~nm}$ \\
\hline after annealing & $434 \mathrm{~nm}$ & $438 \mathrm{~nm}$ & $437 \mathrm{~nm}$ \\
\hline
\end{tabular}




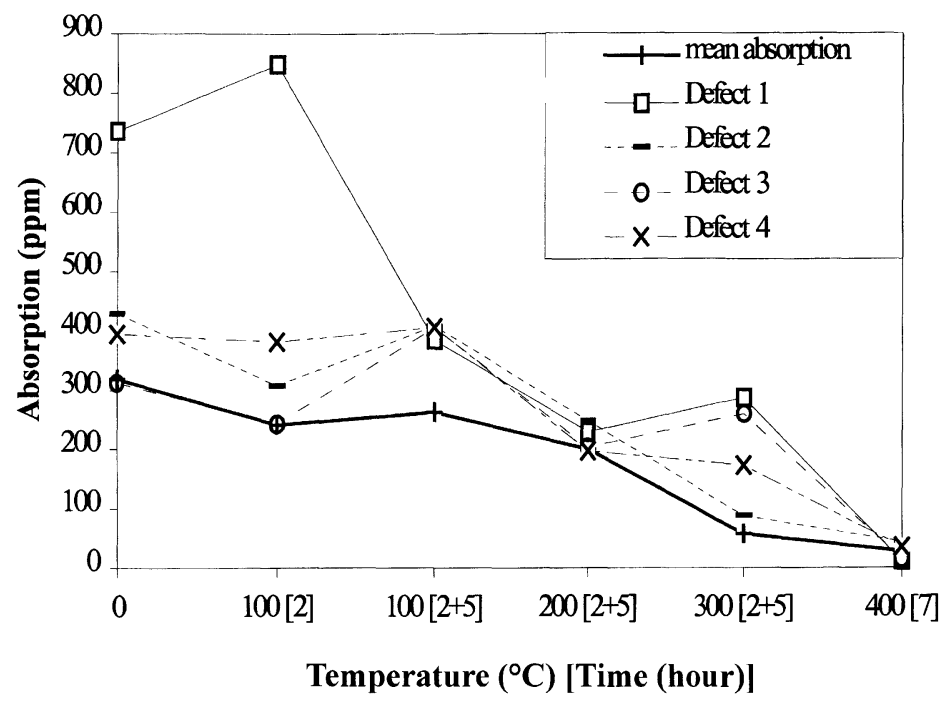

Fig. 3. - Variations of the optical absorption after successive annealings.

We can therefore conclude that annealing at $400{ }^{\circ} \mathrm{C}$ for few hours applied to $\mathrm{Ta}_{2} \mathrm{O}_{5}$ films can reduce the stress in thin films as well as the mean absorption and the absorption on localized defects. This thermal action might be efficient to improve the laser damage threshold since obviously reducing absorption decreases laser induced thermal stress. Moreover thermal annealing at $400{ }^{\circ} \mathrm{C}$ seems to suppress the anisotropy of the $\mathrm{Ta}_{2} \mathrm{O}_{5}$ layers and decrease their refractive index. These transition like effects might be related to changes in the films microstructure and studies are now into progress to clarify these points.

\section{Implantation}

Ion implantation is commonly used to change the mechanical, electrical, chemical and optical properties of materials [9]. Therefore applying this technique is attractive to attempt to modify the stress in thin films. As a first approach we decide to test the effects of ion implantation in $\mathrm{Ta}_{2} \mathrm{O}_{5}$ layers, either in the thin films themselves or in the near surface of the substrate. However, it must be noticed that in the latter case the ions passing through the layers transfer their energy by ionization processes. We use $\mathrm{Xe}^{+}$and $\mathrm{He}^{+}$ions - which highly differ from one another in mass - accelarated at energy in the MeV range by means of a Van de Graaff.

Afterwards, we only look at the deflection of the center and not the stress. As a matter of fact, because of the Gaussian-like concentration profile of the implanted ions, a layer irradiated by $\mathrm{Xe}^{+}$ions can no longer be considered as homogeneous. Therefore, the stress can no more be assumed to be constant within the film and this one has to be considered as a multilayer stack. In the case of $\mathrm{He}^{+}$irradiation, the substrate has to be considered as a multilayer stack.

$\mathrm{Xe}^{+}$implantations have been performed at an energy of $1.5 \mathrm{MeV}$, and at various doses ranging from $10^{12}$ to $10^{16}$ at $/ \mathrm{cm}^{2}$. The ions concentration profile ranges calculated by Transfer of Ions in Matter simulation (TRIM, [10]) are given in Figure 4. Obviously, the implanted ions are expected to be only localized in the thin film. Moreover, it must be noted that, since the xenon mass is high, the rate of deposited energy by nuclear collisions, as deduced from the TRIM calculations, is also quite high: $60 \%$. Thus, recoils phenomena are quite important and the sputtered layer is about $5 \mathrm{~nm}$ thick. 


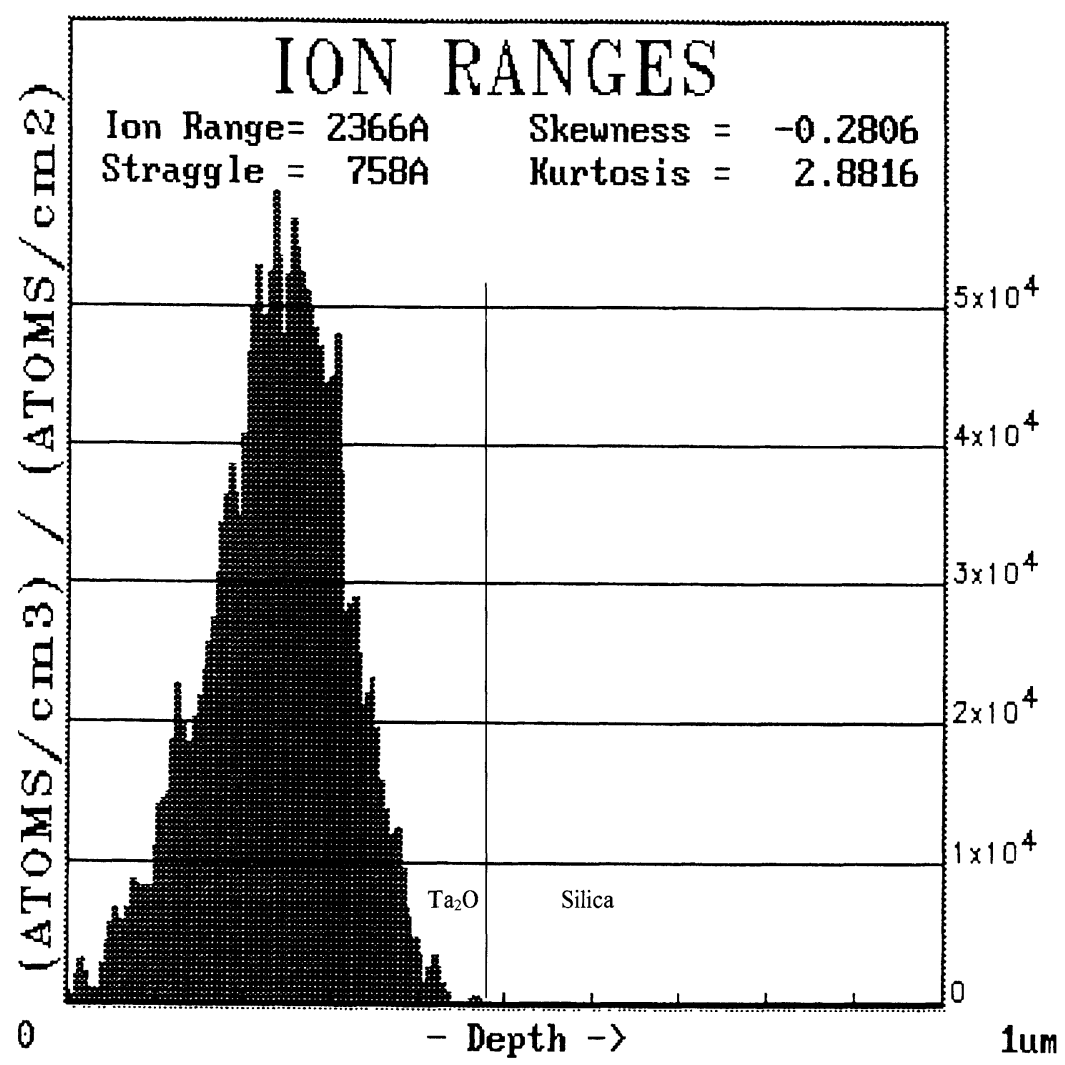

Fig. 4. - TRIM calculations for xenon implantations, ion concentration profile ranges.

There are variations of deflection indeed from $10^{12}$ to about $10^{16}$ at $/ \mathrm{cm}^{2}$ (which represents the overall ion dose variation range), as can be seen in Figure 5. From $10^{12}$ to about $5 \times 10^{13}$ at $/ \mathrm{cm}^{2}$, there is nearly no change, although a very weak compressive stress is generated. For stronger doses, an important tensile stress seems to be generated, increasing with the dose up to a saturation state. For a dose of about $6 \times 10^{13} \mathrm{at} / \mathrm{cm}^{2}$, implantation induces no change in the bending, and for a dose of about $2 \times 10^{14}$ at $/ \mathrm{cm}^{2}$, the thin film is no more bended and can be considered as plane.

In the same way, $\mathrm{He}^{+}$implantations are performed at a constant energy, $1 \mathrm{MeV}$, and with doses from $5 \times 10^{15}$ to $1.5 \times 10^{17}$ at $/ \mathrm{cm}^{2}$. The concentration profile of the implanted ions obtained from TRIM calculation is given in Figure 6. Helium implantation effects are completely different from the xenon one. Because helium ions are very light, they are implanted deeply in the substrate. Furthermore, since they loose $99 \%$ of their energy by ionization processes there is no sputtered layer.

As can be seen in Figure 7, there are important variations of deflection when the implantation dose changes from $5 \times 10^{15}$ to about $5 \times 10^{16}$ at $/ \mathrm{cm}^{2}$. For higher doses values, no more change in the bending seems to occur. It must be noted that for a dose of about $4 \times 10^{16} \mathrm{at} / \mathrm{cm}^{2}$, the thin film is no more bended and can thus be considered as plane. 


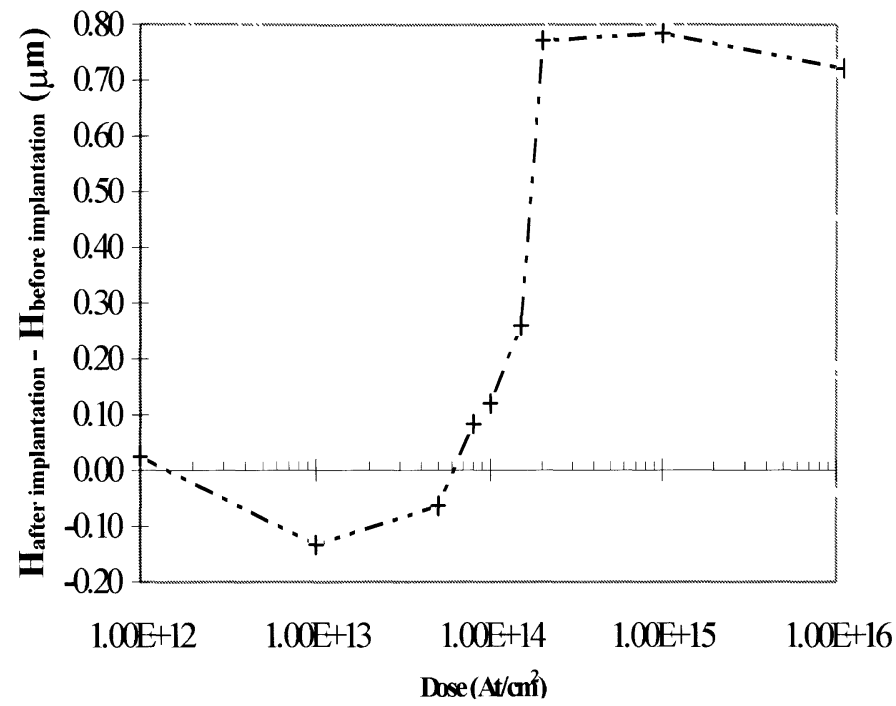

Fig. 5. - Variations of the deflection after implantation versus the doses of xenon.

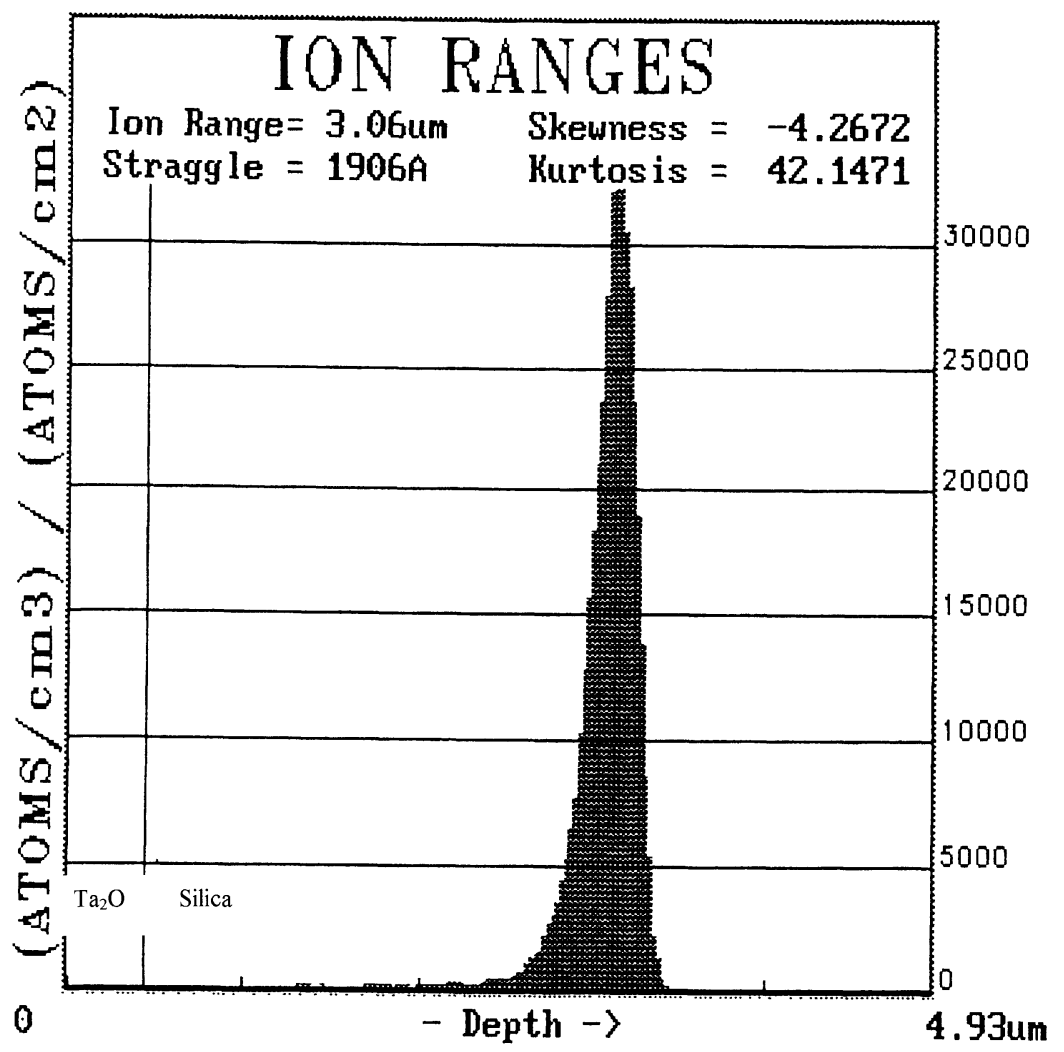

Fig. 6. - TRIM calculations for helium implantations, ion concentration profile ranges. 


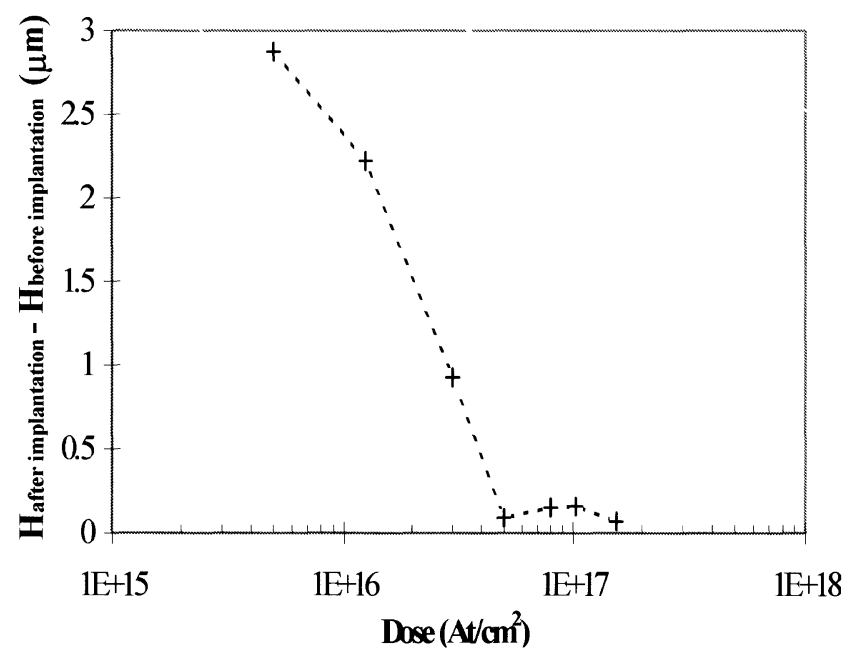

Fig. 7. - Variations of the deflection after implantation versus the doses of helium.

We can therefore conclude that ion irradiation of thin films by energetic ions does strongly modify their original stress. Helium irradiation seems, at a first glance, more efficient to alter our $\mathrm{Ta}_{2} \mathrm{O}_{5}$ layers than xenon. But, in both cases, we demonstrate that a zero bending of the layer can be achieved.

\section{Conclusion}

We have investigated stress and optical properties of $\mathrm{Ta}_{2} \mathrm{O}_{5}$ and $\mathrm{SiO}_{2}$ layers made by RLVIP technique. An elastic model has been used to measure the compressive stress in this type of layers and has been extended in order to predict the bending of a multilayer plate. Good agreement between experiment and calculations has been observed. This key result demonstrates that the layer to layer interactions turn out to be negligible and that the stack deflection can be well predicted when the intrinsic stress of each individual material are known. Furthermore, a detailed study of thermal annealing in RLVIP $\mathrm{Ta}_{2} \mathrm{O}_{5}$ have showed that at $400{ }^{\circ} \mathrm{C}$ the stress undergoes a strong transition from compressive to tensile associated with a significant decrease of the optical absorption in the layer. This result should be used with benefit to increase the laser damage threshold in $\mathrm{cw}$ excitation regime.

Finally, our preliminary investigations concerning the ion implantation effects on thin film stress demonstrate that the bending of the deposited films is strongly dependent on the ion dose and the nature of the implanted ions, and even more that a zero bending can be achieved. Although requiring further investigations, these results are of practical interest in thin film technology to modify and control the stress of optical coatings.

\section{Acknowledgments}

The authors are grateful to G. Albrand for the realization of the coatings. 


\section{References}

[1] Doerner M.F. and Nix W.D., Crit. Rev. Solid State Sci. 14 (1988) 225-268.

[2] Windischmann H., J. Appl. Phys. 62 (1987) 1800-1807.

[3] Leplan H., Robic J.Y. and Pauleau Y., J. Appl. Phys. 79 (1996) 6926-6931.

[4] Pulker H.K., Coating on glass (Elsevier, Amsterdam, 1984) pp. 247-256.

[5] Stoney G.G., Proc. R. Soc. London Ser. A82 (1909) 172-175.

[6] Townsend P.H., Barnett D.M. and Brunner T.A., J. Appl. Phys. 62 (1987) 4438-4444.

[7] Flory F., Albrand G., Endelema D., Maythaveekulchai N., Pelletier E. and Rigneault H., Opt. Eng. 33 (1994) 1669-1667.

[8] Commandré M. and Roche P., Characterization of absorption by photothermal deflection, Thin films for optical systems (Marcel Dekker Inc., New-York, 1995) pp. 329-366.

[9] Favennec P.N., L'implantation ionique (Masson, Paris, 1993).

[10] Ziegler J.F., Biersack J.P. and Litmark U., The stopping power and ranges of ions in solids (Pergamon Press, New York, 1988). 